\title{
600 mg Oxcarbazepine Tablets Bioequivalence Study
}

\section{Vargas $\mathbf{M}^{1 *}$ and Villarraga $\mathrm{EA}^{2}$}

1 Unidad de Farmacología Universidad de la Sabana, Bogotá, Colombia

${ }^{2}$ Pharmacologist, Study Medical Coordinator, Bogotá, Colombia

\begin{abstract}
Bioequivalence studies are evidence of generic drugs quality, demonstrating that the rate and quantity of effective substance absorbed from each of the studied formulations, showed no significant differences. The aim of the pharmacokinetic study of the two formulations, containing $600 \mathrm{mg}$ of Oxcarbazepine, is to analyse bioavailability between the Test Product (Oxicodal ${ }^{\circledR}$ from Synthesis Laboratory S.A.S, Colombia) and the Reference Product (Trileptal ${ }^{\circledR}$ from Novartis Laboratory) and to affirm the Bioequivalence. Therefore, a study was developed in 24 healthy volunteers; an open, four periods and four randomized sequences, with one dose of $600 \mathrm{mg}$ during fasting and postprandial conditions, and 7-day wash time between each period study. Conducting the study in 4 periods obeys the need to know if there are differences in relation to the presence or not of food during the bioavailability of the formulations studied. The benefits sought in this study are to offer public health a guarantee of quality, safety and inter-changeability of the drugs studied to increase the population's access to generic medicines.

The analytical method used was HPLC chromatography UV detector. The $90 \%$ confidence interval for the parameters $C_{m a x}, A \cup C_{0-t}$ and $A \cup C_{0-\infty}$, according to European guidelines and the FDA is within the permitted ranges for the declaration of bioequivalence and compatibility of the Synthesis S.A.S (Colombia) product Oxicodal ${ }^{\circledR}$, with the Novartis Laboratories Reference Product Trileptal ${ }^{\circledR}$, for both feeding conditions, fasting and postprandial.
\end{abstract}

Keywords: Bioequivalence; Oxcarbazepine; Anticonvulsant; Pharmacokinetic

\section{Introduction}

Oxcarbazepine is indicated as an anticonvulsant in the treatment of partial and generalized conditions [1]. Oxcarbazepine acts by altering the activity of the basic mediators of neuronal excitability, either on the mediators of voltage-dependent ionic channels (sodium channels blockade at brain level), or those controlled by neurotransmitters. It also increases potassium conductance and modulates the calcium channels activity [2]. Oxcarbazepine is a keto-analog of carbamazepine, which is considered a prodrug because of its rapid metabolism to a monohydroxy derivative. Its particular structure helps to reduce the impact on liver metabolism associated with carbamazepine.

This study aims to establish Bioequivalence between two formulations of $600 \mathrm{mg}$ Oxcarbazepine tablets when comparing their bioavailability following a single dose, between the Synthesis S.A.S Test Product (Colombia) and the Novartis Trileptal' Reference Product, in both fasting and postprandial feeding conditions.

\section{Materials and Methods}

\section{Study of formulations}

Test medicament: $600 \mathrm{mg}$ Oxcarbazepine tablets produced and distributed in Colombia by Synthesis S.A.S Laboratories Lot 6A0765.

Reference medicament: Trileptal $600 \mathrm{mg}$ Oxcarbazepine tablets, produced and distributed by Novartis; Lot Z00323.

\section{Subjects}

For admission to the study, were taken into account healthy volunteers of both genders, non-smokers, over 18 years of age.

Volunteers underwent medical and laboratory evaluations that included HIV and Hepatitis tests, so that to be diagnosed as healthy before the clinical phase. Women additionally underwent pregnancy test to make sure they were not pregnant. History of alcoholism, drug abuse or pre-existing diseases, were treated as exclusive factors.

\section{Obtaining informed consent}

The Protocol and Informed Consent were certified by an independent Ethics Committee, which is authorized by the National Regulatory Authorities, and is governed by the guidelines of the World Conference on Harmonization for Good Clinical Practices for institutions that promotes research in human beings, and by the theory and concept of World Medical Assembly, published in the Declaration of Helsinki [3].

The consent was taken after an individual talk to the volunteers, whose purpose was to explain the study in detail, indicating the variety of drug to be used, the dose, the possible adverse drug reactions, the volume of blood that would be drawn at each stage of study, the dietary restrictions they would face, and answering all questions they had so they could freely decide their participation in the study.

\section{Study design}

It was applied as an open, crossed, randomized design, of four periods, four sequences, and a wash time of 7 days during every period. Three days before the beginning of each period, volunteers had to refrain from taking any medication, alcohol and any food or drink containing methylxanthines. This condition was followed during the collection of the samples. All volunteers were randomized and assigned for the sequence of treatment.

\section{Sample taking and drug administration}

The process of collection of samples was carried out by a medicine

*Corresponding author: Vargas M, D.D.S., Pharmacologist, Scientific Director Unidad de Farmacología Universidad de la Sabana, Bogotá, Colombia, Tel: 55523-34/8106; E-mail: mauricio.vargas@unisabana.edu.co

Received June 14, 2017; Accepted July 25, 2017; Published August 04, 2017

Citation: Vargas M, Villarraga EA (2017) 600 mg Oxcarbazepine Tablets Bioequivalence Study. J Bioequiv Availab 9: 489-492. doi: 10.4172/jbb.1000350

Copyright: @ 2017 Vargas M, et al. This is an open-access article distributed under the terms of the Creative Commons Attribution License, which permits unrestricted use, distribution, and reproduction in any medium, provided the original author and source are credited. 
doctor and a licensed nurse. Using a Vacutainer, the blood sample was collected by venepuncture in the upper limb. For periods 1 and 2, volunteers were allowed to fast for $10 \mathrm{hrs}$, prior to the drug administration, either the Test Product or the Reference Product, which randomly corresponded to each volunteer. The drug dose administered in each period was $600 \mathrm{mg}$, with $200 \mathrm{~mL}$ of water, and the volunteers were allowed to take food only after $4 \mathrm{hrs}$ from the administration of drug [4].

During study periods 3 and 4 , in postprandial condition, the volunteers were given standardized diet which was designed by the Nutrition Department of Clínica La Sabana, based on a diet for breakfast that had high lipid content (approximately 50 percent of the total caloric food content) and high in calories (approximately 800 to $1000 \mathrm{kcal}$ ), which was programmed in approximately $150 \mathrm{kcal}$ of proteins, $250 \mathrm{kcal}$ of carbohydrates and 500-600 kcal of lipids According to international recommendations [4]. After half an hour, all volunteers were given either the Test Product or the Reference Product, according to randomization. 12 venous blood samples of $8 \mathrm{~mL}$ each, were taken at the time intervals of: $0 \mathrm{hr}$ (immediately prior to administration of the drug) $1,2,2.5,3,4,5,6,8,12,24$ and $48 \mathrm{hrs}$ after. Labelling of samples was done for identification and then centrifuged at $3000 \mathrm{rpm}$ for $30 \mathrm{~min}$. Plasma was transferred to a previously labelled tube and frozen at $-80^{\circ} \mathrm{C}$ for further analysis. After 7 days of wash time, the same procedure was repeated, completing periods 2,3 and 4 .

\section{Validation of the analytical method}

The bioanalytical method used for the analysis of Oxcarbazepine in plasma, was high performance liquid chromatography with Ultra Violet detection (HPLC-UV).

For the sample preparation, sedimentation was carried out by adding $475 \mu \mathrm{L}$ of the test sample to a screw cap centrifuge tube that already contained $25 \mu \mathrm{L}$ of Internal Standard (ISTD) (carbamazepine) (5000 ng/ $\mathrm{mL}$ ). Then this mixture was added with $200 \mu \mathrm{l}$ of $60 \%$ perchloric acid and vortexed for $3 \mathrm{~min}$ at $1500 \mathrm{rpm}$ to precipitate the proteins. Finally, it was centrifuged at $5000 \mathrm{rpm}$ for $10 \mathrm{~min}$; then the supernatant was filtered with membrane $-0.45 \mu \mathrm{m}$ and added to the chromatographic system $[5,6]$.

Analyte dissolution was attained by using a Symmetry Shield" C18, 4, $6 \mathrm{~mm} \times 150 \mathrm{~mm}, 5 \mu \mathrm{m}$ Column, at a $40^{\circ} \mathrm{C}$ temperature, employing a HPLC SHIMADZU LC2010, with $215 \mathrm{~nm}$ wave length. The detection limit is $28.0 \mathrm{ng} / \mathrm{mL}$, and the quantification limit is $50.0 \mathrm{ng} / \mathrm{mL}$. Both limits are low, which allows making a calibration curve in a broader range towards lower concentrations.

\section{Pharmacokinetic analysis}

By using the WinNonlin 5.3 program (Pharsight Corporation, Cary USA) the Pharmacokinetic study was executed, through a noncompartmental analysis. The maximum concentration $\left(\mathrm{C}_{\max }\right)$ and the time to reach it $\left(\mathrm{t}_{\max }\right)$, were calculated from the plasma concentrations readings, as currently approved by FDA [7] and the EMA (European Medicines Agency) [8]. The $\mathrm{AUC}_{\text {total }}$ was estimated by the addition of the partial AUCs: a) $\mathrm{AUC}_{0-\mathrm{t}}$, between zero and the final time point with noticeable concentrations, evaluated by the trapezoidal rule assuring at least $80 \%$ of the AUC with the last sample, b) $\mathrm{AUC}_{\mathrm{t}-\infty}$, estimated as the quotient $\mathrm{C} / \mathrm{K}$, where $\mathrm{C}$ is the last detectable concentration and $\mathrm{K}$ is the slope of the line obtained by linear regression, from the points corresponding to the phase of the drug elimination by linear regression of the natural logarithm of the concentrations [9]. The factors like elimination constant $\left(\mathrm{K}_{\mathrm{e}}\right)$, half-life $\left(\mathrm{t}_{1 / 2}\right)$, clearance $(\mathrm{CI})$, and Mean Residence Time (MRT) were conformed to bioavailability and evaluated after the operation of the non-compartmental analysis.

\section{Statistical analysis}

The Analysis of Variance (ANOVA) was applied to estimate possible effects for each variation factor by sequence, period or subjects. For this, the F-test was used with a level of statistical significance of 5\% $(\alpha=0.05 \%)$. Statistical comparison of the logarithmically transformed pharmacokinetic parameters of the two test/reference formulations was performed using the WinNonlin statistical program for the variables $\mathrm{C}_{\max }, \mathrm{AUC}$ and $\mathrm{AUC}_{\text {all }}$, that should be within the acceptability range of 80-125\%.

\section{Adverse events reporting}

The events were registered according to the INVIMA regulations in Disposition $\mathrm{N}^{\circ}(1067 / 08)$. Since the sample size does not have sufficient statistical power, the cases are reported without statistical estimation.

\section{Results}

In this study, 24 healthy volunteers of both genders (50\% women and $50 \%$ men), of Colombian nationality, who completed the 4 periods, were included in the pharmacokinetic and statistical analysis. Both the analyses were well accepted. Adverse events are presented selecting the in taking condition and the drug studied in relation to the compromised system, according to the OMS recommendation in Table 1.

The averages of the pharmacokinetic parameters, the values of elimination rate, half-life, $\mathrm{C}_{\max }, \mathrm{T}_{\max }, \mathrm{AUC}_{0-\mathrm{t}}$ and $\mathrm{AUC}_{0-\infty}$ of each of the studied formulations obtained from all volunteers and in the two feeding conditions (mean $\pm \mathrm{SD}$ ), are presented in Table 2 .

\begin{tabular}{|c|c|c|c|}
\hline & & \multicolumn{2}{|c|}{ Fasting Condition } \\
\hline & & Reference \% & Test \% \\
\hline \multirow{2}{*}{ Nervous System Disorder } & Dizziness & 4.2 & 4.2 \\
\hline & Drowsiness & 2 & 0,0 \\
\hline & & \multicolumn{2}{|c|}{ Post-prandial Condition } \\
\hline & & Reference \% & Test $\%$ \\
\hline \multirow{6}{*}{ Nervous System Disorder } & Dizziness & 20.8 & 18.7 \\
\hline & Drowsiness & 10.4 & 14.6 \\
\hline & Headache & 8.3 & 2 \\
\hline & Nausea & 2 & 0,0 \\
\hline & Visual Impairment & 2 & 0,0 \\
\hline & Lip Hypoesthesia & 0,0 & 6.2 \\
\hline
\end{tabular}

Table 1: Adverse reactions discriminated by food condition. 
Citation: Vargas M, Villarraga EA (2017) 600 mg Oxcarbazepine Tablets Bioequivalence Study. J Bioequiv Availab 9: 489-492. doi: 10.4172/ jbb. 1000350

The $90 \%$ confidence intervals of the logarithmically transformed pharmacokinetic parameters, executed to analyse the bioequivalence between Oxicodal', Test Product of Synthesis SAS, and Trileptal, Reference Product from Novartis, are shown in Table 3.

\section{Discussion}

Oxcarbazepine becomes a therapeutic alternative as an anticonvulsant in the treatment of partial and generalized symptoms. The reduction in treatment costs of neurological pathologies by generic drugs is a desired goal for any health system in the world. Therefore, bioequivalence studies are a good alternative to demonstrate the quality of generic drugs products and allow inferring interchange ability in relation to Reference Products without the need to repeat clinical studies in patients $[7,8]$.

The methodology of this research with healthy volunteers, allowed determining the formulation effects in the two feeding conditions. The applied analytical method was selective, precise, accurate and robust. The 24 volunteers completed the study and only mild adverse events were reported in both formulations. The washing period was lengthy as compared to the recommended 7 elimination half-lives and guaranteed the absence of the trawling consequence between periods.

This observation aimed to calculate the bioequivalence between two $600 \mathrm{mg}$ Oxcarbazepine formulations. In Graphs 1 and 2, the curves of the mean plasma concentrations vs. time are presented. They are similar for the two feeding conditions. On the other hand, $90 \%$ confidence intervals of the proportions test/reference for the evaluated criteria $\mathrm{C}_{\max }, \mathrm{AUC}_{0-\mathrm{t}}$ and $\mathrm{AUC}_{0-\infty}$, meet the range requested by the FDA and the EMA (Table 4) $[7,8]$.

The usage of a single dose layout limited our examination, including healthy women and men. Because the examination was performed on

\begin{tabular}{|c|c|c|c|c|c|c|}
\hline \multicolumn{7}{|c|}{ Fasting Condition } \\
\hline Treatment & Elimination Rate $(1 / \mathrm{hr})$ & Half-life (hr) & $t_{\max }(h r)$ & $C_{\max }(n g / m L)$ & $A U C_{0-t}\left(h r^{*} n g / m L\right)$ & $A U C_{0-\operatorname{lnf}}\left(\mathrm{hr} r^{*} \mathrm{gg} / \mathrm{mL}\right)$ \\
\hline Reference & 0,142 & 6,9 & 2,0 & 3135,8 & 14530,8 & 14844,5 \\
\hline Test & 0,136 & 6,8 & 2,0 & 3209,5 & 15723,7 & 15809,6 \\
\hline \multicolumn{7}{|c|}{ Fed Condition } \\
\hline Treatment & Elimination Rate $(1 / \mathrm{hr})$ & Half-life (hr) & $t_{\text {máx }}(h r)$ & $C_{\max }(n g / m L)$ & $A U C_{0-t}\left(h r^{*} n g / m L\right)$ & $A U C_{0-\operatorname{lnf}}\left(\mathrm{hr} r^{*} \mathrm{~g} / \mathrm{mL}\right)$ \\
\hline Reference & 0,193 & 4,4 & 2,0 & 3282,3 & 13368,7 & 13164,4 \\
\hline Test & 0,175 & 7,6 & 2,0 & 3283,1 & 14488,2 & 14464,9 \\
\hline
\end{tabular}

Table 2: Averages of pharmacokinetic parameters discriminated by feeding condition.

\begin{tabular}{|c|c|c|c|c|}
\hline \multirow[b]{2}{*}{ Parameter } & \multirow[b]{2}{*}{ Units } & \multirow[b]{2}{*}{ Ratio \% } & \multicolumn{2}{|c|}{ Standard $90 \% \mathrm{Cl}$ Test/Reference } \\
\hline & & & 80 & 125 \\
\hline $\operatorname{Ln}\left(C_{\max }\right)$ & $\mathrm{ng} / \mathrm{mL}$ & 102,68 & 99,98 & 105,46 \\
\hline $\operatorname{Ln}\left(\mathrm{AUC}_{\text {all }}\right)$ & hr*ng/mL & 107,19 & 99,17 & 115,86 \\
\hline $\operatorname{Ln}\left(\right.$ AUC $\left._{\text {INF_-Obs }}\right)$ & $\mathrm{hr}{ }^{*} \mathrm{ng} / \mathrm{mL}$ & 106,01 & 97,37 & 115,42 \\
\hline
\end{tabular}

Table 3: Confidence Intervals of $90 \%$, discriminated by feeding condition. Bioequivalence analysis (Confidence Interval $80-125)$ fasting condition.

Bioavailability curve obtained after a $600 \mathrm{mg}$ Oxcarbazepine (Oxicodal ${ }^{\circledR}$ from Synthesis S.A.S) and Reference Product (Trileptal ${ }^{\circledR}$ from Novartis). fasting conditions

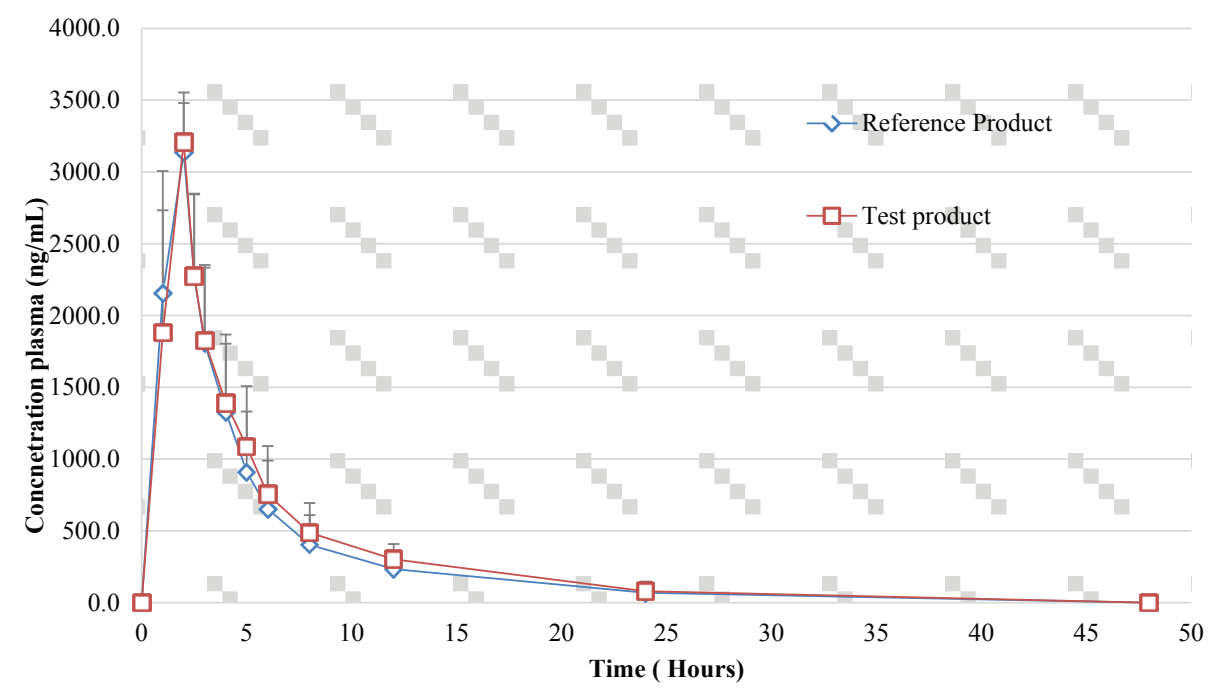

Graph 1: Bioavailability curve (Concentration vs. Time) obtained after a 600 mg Oxcarbazepine dose in fasting conditions of Test Product (Oxicodal ${ }^{\circledR}$ from Synthesis S.A.S) and Reference Product (Trileptal ${ }^{\circledR}$ from Novartis). 
Citation: Vargas M, Villarraga EA (2017) 600 mg Oxcarbazepine Tablets Bioequivalence Study. J Bioequiv Availab 9: 489-492. doi: 10.4172/ jbb.1000350

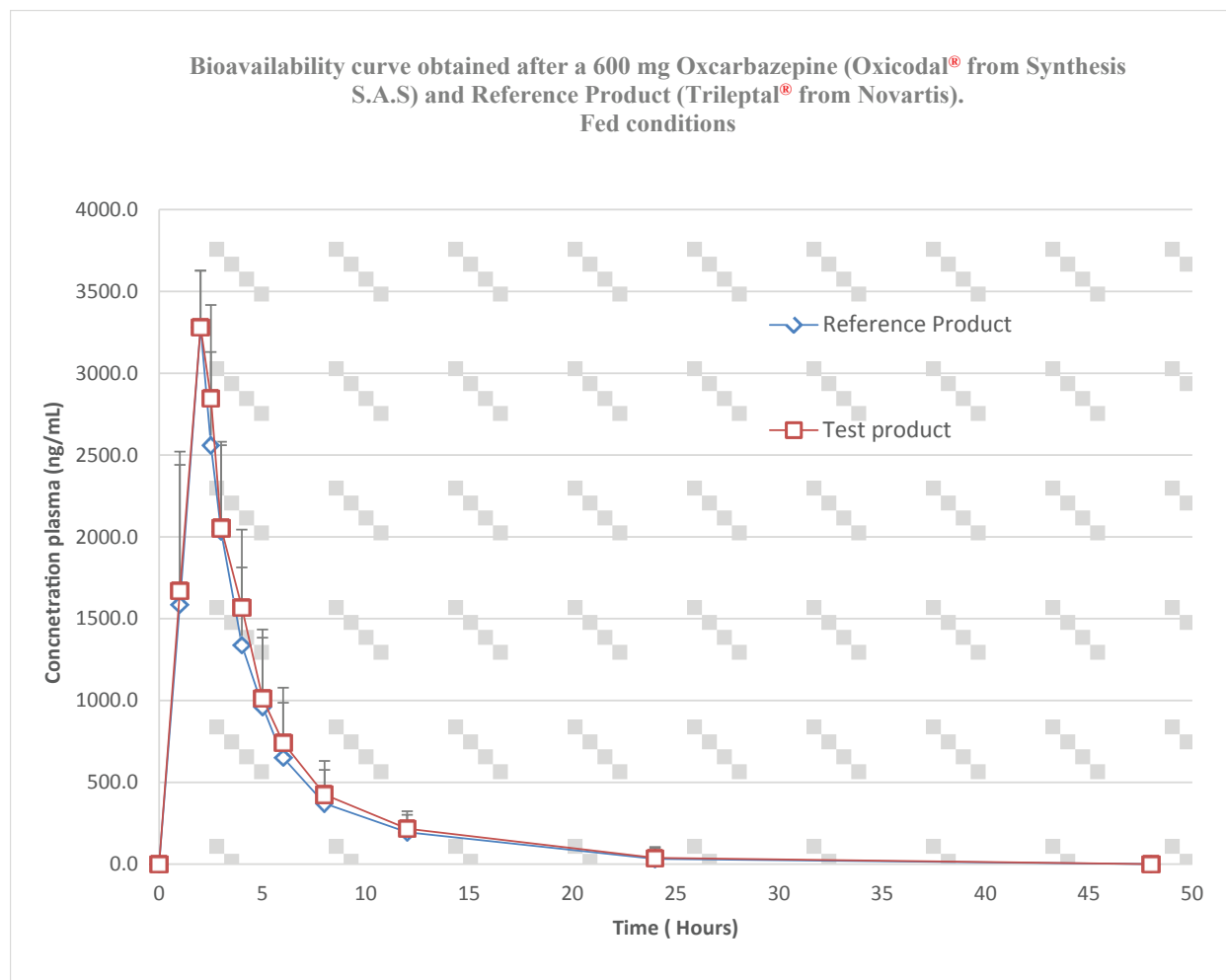

Graph 2: Bioavailability curve (Concentration vs. Time) obtained after a 600 mg Oxcarbazepine dose in post prandial condition of Test Product (Oxicodal ${ }^{\circledR}$ from Synthesis S.A.S) and Reference Product (Trileptal ${ }^{\circledR}$ from Novartis).

\begin{tabular}{|c|c|c|c|c|}
\hline \multirow[b]{2}{*}{ Parameter } & \multirow[b]{2}{*}{ Units } & \multirow[b]{2}{*}{ Ratio \% } & \multicolumn{2}{|c|}{ Standard $90 \% \mathrm{Cl}$ (Test/Reference) } \\
\hline & & & 80 & 125 \\
\hline $\operatorname{Ln}\left(C_{\max }\right)$ & $\mathrm{ng} / \mathrm{mL}$ & 99,77 & 97,88 & 101,70 \\
\hline $\operatorname{Ln}\left(A \cup C_{\text {all }}\right)$ & hring/mL & 107,57 & 102,00 & 113,44 \\
\hline $\operatorname{Ln}\left(A \cup C_{\text {INF }-}\right.$ obs $)$ & hring/mL & 109,47 & 103,85 & 115,39 \\
\hline
\end{tabular}

Table 4: Bioequivalence analysis (Confidence Interval 80-125) fed condition.

healthy volunteers, the results are not relative to the patient population or those to having significant medical conditions.

\section{Conclusion}

The Oxcarbazepine formulation manufactured by Synthesis S.A.S (Oxicodal $)^{\circ}$, Test Product, and the one manufactured by Novartis (Trileptal'), Reference Product, have pharmacokinetic parameters that allow declaring bioequivalence between the two formulations, in the two feeding conditions evaluated.

\section{References}

1. Lloyd P, Flesch G, Dieterle W (1994) Clinical pharmacology and pharmacokinetics of oxcarbazepine. Epilepsia 35: S10-S13.

2. Glauser TA (2011) Oxcarbazepine in the treatment of epilepsy. Pharmacotherapy 21: 904-901.

3. World Medical Association Declaration of Helsinki (2008) $59^{\text {th }}$ general assembly Seoul, Korea.

4. http://www.fda.gov/Drugs/GuidanceComplianceRegulatory/nformation/ Guidances.htm
5. Juenke JM, Brown PI, Urry FM, McMillin GA (2006) Drug monitoring and toxicology: a procedure for the monitoring of oxcarbazepine metabolite by HPLC-UV. J Chromatogr Sci 44: 45-48.

6. Haq KU, Kumar N (2014) Development and validation of LC-MS/MS method for the simultaneous quantitative analysis of oxcarbazepine and its metabolite 10-hydroxycarbazepine in k2edta plasma. Int J Pharm Pharm Sci 6: 422-429.

7. Food and Drugs Administration (2009) January, guidance for industry: statistical approaches to establishing bioequivalence.

8. The European Agency for the Evaluation of Medicinal Products (EMA) (2001) Committee for Proprietary Medicinal Products (CPMP). London, UK.

9. Perry R (2010) Perspectives on the bioequivalence and therapeutic equivalence of generic formulations: An overview of the landscape. Clin Ther 32: 17961797. 